\title{
O RECONHECIMENTO DAS CERTIFICAÇÕES AMBIENTAIS NO SETOR DA CONSTRUÇÃO CIVIL
}

\section{THE RECOGNITION OF ENVIRONMENTAL CERTIFICATIONS IN THE CIVIL CONSTRUCTION SECTOR}

\author{
Danielle Elis Garcia Furuya'; Michelle Taís Garcia Furuya²; Rodrigo Coladello \\ de Oliveira ${ }^{3}$ \\ ${ }^{1}$ Universidade do Oeste Paulista - UNOESTE,curso de Engenharia Ambiental e Sanitária da \\ Presidente Prudente, SP. \\ ${ }^{2}$ Toledo Prudente Centro Universitário, curso de Arquitetura e Urbanismo, Presidente Prudente, \\ SP. \\ e-mail: michellegfuruya@gmail.com \\ ${ }^{3}$ Mestre em Meio Ambiente e Desenvolvimento Regional pela Universidade do Oeste Paulista - \\ (UNOESTE), Presidente Prudente, SP.
}

RESUMO - A adoção de práticas sustentáveis tem se tornado cada vez mais comum na área profissional. A fim de evitar o desperdício de materiais e utilizar produtos que causem menor impacto ambiental, o setor da construção civil busca colocar em prática a sustentabilidade. As certificações ambientais recebem um papel fundamental nesse setor como uma forma de garantir que tais práticas são realizadas corretamente. Nesse contexto, o objetivo do artigo foi realizar um estudo sobre o papel das certificações ambientais no setor da construção civil, levando em consideração a forma como são divulgadas e aplicadas. Apesar dos profissionais da área terem conhecimento da possibilidade de uma edificação receber certa certificação, verificou-se que as informações referentes ao conceito e ao processo para obtenção de uma certificação ambiental são escassas.

Palavras-chave: certificações ambientais, construção civil, sustentabilidade.

ABSTRACT - The adoption of sustainable practices has become increasingly common in the professional field. In order to avoid wasting materials and using products that cause less environmental impact, the construction industry seeks to put sustainability into practice. Environmental certifications play a key role in this sector as a way to ensure that such practices are performed correctly. In this context, the objective of the article was to conduct a study on the role of environmental certifications in the civil construction sector, taking into account the way they are disclosed and applied. Although the professionals of the area are aware of the possibility of a building receiving a certain certification, it was verified that the information regarding the concept and the process to obtain an environmental certification are scarce.

Keywords: civil construction, environmental certifications, sustainability. 


\section{INTRODUÇÃO}

O setor da construção civil exige cada vez mais a adoção de práticas sustentáveis, desde o início e planejamento de uma obra até o período de inauguração e funcionamento. Uma das práticas que recebem destaque são as certificações ambientais, que traz diversos benefícios além de agregar valor a uma edificação e contribuir com a redução de custos.

A certificação ambiental surge como uma forma de se estabelecer, em âmbito e escala global, índices, padrões, standards e conceitos ambientais para a produção de produtos e serviços no mercado (VIDIGAL, 2012). Essas certificações são normativas que estabelecem um padrão de planejamento, construção, gestão e comercialização de empreendimentos, consiste na declaração, efetuada por um organismo de certificação, de que um produto, processo ou sistema está conforme requisitos especificados (ZANGALLI, 2013).

Existem diferentes certificações ambientais para as empresas. Segundo Zangalli, 2013 não há entre elas um padrão técnico de sustentabilidade, sendo que cada uma adota a que melhor couber dentro de suas especificações. As técnicas de avaliação de uma certificação podem acontecer levando em consideração a análise estatística, baseados em créditos que geram índices e baseado no desempenho (LEITE, 2011).

Nesse contexto, o objetivo deste artigo foi realizar um estudo sobre o papel das certificações ambientais no setor da construção civil, analisando a constante evolução quanto à disseminação do tema. A pesquisa consiste em uma continuidade do trabalho realizado pelos autores onde os resultados obtidos pela pesquisa autoral são analisados de forma mais aprofundada.

\section{METODOLOGIA}

O estudo ocorreu em três etapas conforme mostrado no fluxograma (Figura 1).
Figura 1. Etapas realizadas durante a pesquisa.

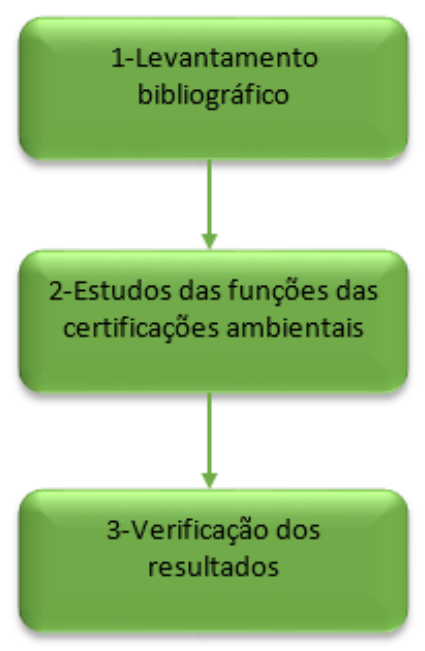

Fonte: (Autores, 2018).

Foram realizados estudos sobre o tema através de uma pesquisa feita por Furuya e Oliveira, 2017. Através dos resultados obtidos no Gráfico 2, foram feitas observações a respeito do conhecimento de algumas das certificações.

Gráfico 1. Parte do questionário realizado por Furuya e Oliveira, 2017 com engenheiros civis e arquitetos.

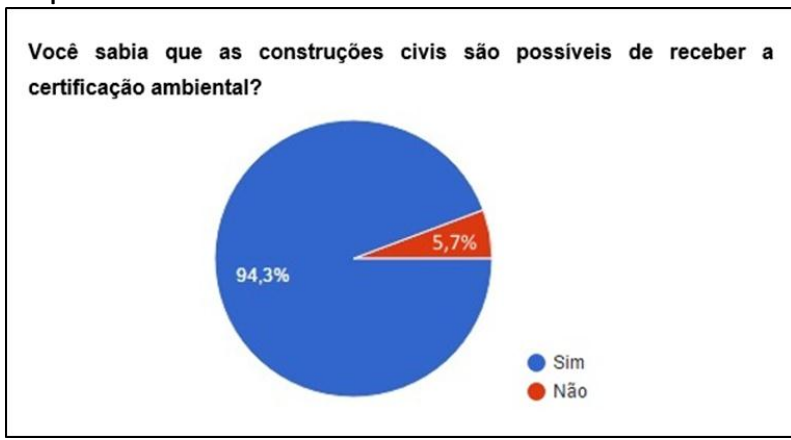

Fonte: (Furuya e Coladello, 2017).

Gráfico 2. Parte do questionário realizado por Furuya e Oliveira, 2017 com engenheiros civis e arquitetos.

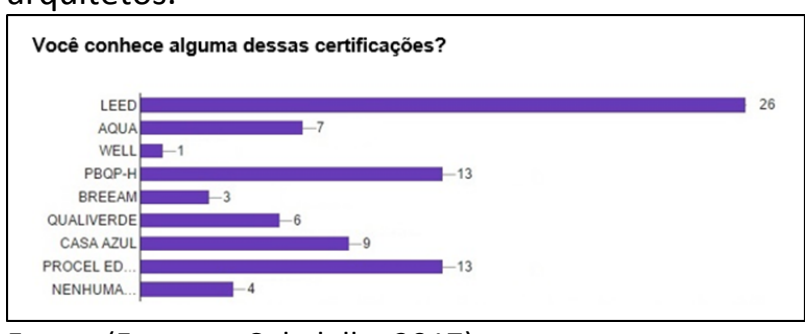

Fonte: (Furuya e Coladello, 2017). 


\section{RESULTADOS}

O conhecimento das certificações ambientais por parte de profissionais do setor da construção civil é amplo, porém de modo superficial. De acordo com os estudos verificouse a deficiência de informações a respeito do tema.

\subsection{Desempenho das Certificações Ambientais}

A crescente demanda por produtos e serviços ecológicos resulta, muitas vezes, em publicidades falsas, pois em meio à busca pelo consumo verde diversas empresas alegam ser ecologicamente corretas sem fornecer provas concretas de tal feito. Surge, então, a desconfiança por parte dos clientes que diante de tantas divulgações e promoções de sustentabilidade não sabem ao certo quem e quais empresas realmente assumiram a responsabilidade de seguir os princípios sustentáveis. (DIAS, 2009).

Diante da situação as empresas buscam soluções estratégicas que possam trazer garantias ao consumidor de que a publicidade verde se trata de informações verídicas. As certificações ambientais aparecem, portanto, como o meio mais eficiente para tal comprovação. O sistema de certificação funciona como um diferencial que um determinado produto ou negócio pode apresentar em relação aos concorrentes tradicionais, constituindo-se em uma ferramenta que impulsiona a competitividade. (DIAS, 2009).

No setor da construção civil as certificações ambientais voltadas às edificações sustentáveis correspondem a um sistema de avaliação que indica através de dados quantitativos e mensuráveis o nível de inserção de princípios sustentáveis em uma determinada construção. Quando a obtenção de uma certificação é almejada diversos fatores devem receber atenção especial, desde métodos construtivos até materiais de acabamento. Isso porque cada modelo de certificação estabelece requisitos próprios, sendo essencial, portanto, o conhecimento das aplicações da certificação desejada. O sistema de certificação ambiental na construção civil pode variar de acordo com o país, assim como pode atingir escala mundial como a certificação LEED (Leadership in Energy and Environmental Design) por exemplo. (KEELER E BURKE, 2010).
Segundo Keeler e Burke (2010, p. 256) “ Hoje, praticamente todas as nações industrializadas têm pelo menos um sistema de certificação de edificações sustentáveis." As diretrizes referentes aos princípios sustentáveis podem ser presenciadas mesmo em países menos desenvolvidos ou de pequeno porte. (KEELER E BURKE, 2010).

Entretanto se por um lado a preocupação com a sustentabilidade é notável, por outro há as críticas que interpretam as certificações, até o momento, como sistemas falhos. Segundo os críticos o sistema de certificação não representa um real interesse em disseminar as práticas sustentáveis por não se aprofundarem nas questões referentes à sustentabilidade, apenas tratar do tema superficialmente. Outros alegam que a falta de uma regra universal dificulta a definição e o entendimento do conceito de certificação. Há ainda os que defendem o fato de que esse sistema incentiva o cumprimento de aspectos mínimos com o único intuito de atingir o suficiente para a obtenção do certificado, além de desviar a intenção das certificações para o campo econômico. (KEELER E BURKE, 2010).

\subsection{Conhecimento das Certificações Ambientais}

Segundo a pesquisa feita por Furuya e Oliveira, 2017 (Gráfico 2) o modelo de certificação mais conhecido é a certificação LEED correspondendo à aproximadamente $74,28 \%$ dos entrevistados. Tendo em vista a possibilidade de mais de uma resposta por entrevistado na questão, é possível concluir que em alguns casos a certificação LEED é a única certificação ambiental conhecida.

A certificação BREEAM (Building Research Establishment Environmental Assessment Method) foi desenvolvida no /Reino Unido e corresponde à uma das certificações mais antigas e uma das mais adotadas. Já a certificação AQUA (Alta Qualidade Ambiental) corresponde à uma adaptação brasileira do HQE (Haute Qualité Environnementale) da França. Apesar do intenso conhecimento e aplicação, ambas obtiveram um número relativamente baixo segundo a pesquisa, o que indica que os profissionais desconhecem estes sistemas de certificação.

A baixa pontuação da maior parte das alternativas indica que apesar de os profissionais terem $o$ conhecimento da existência das certificações ambientais voltadas à construção civil, poucos conhecem o assunto em termos mais aprofundados relacionados ao nome, à 
função e ao processo de aplicação e funcionamento por exemplo.

\section{DISCUSSÃO}

Segundo Vidigal, 2012, a certificação ambiental, quando mantida pela empresa, atua como um mecanismo de defesa do meio ambiente ecologicamente equilibrado, garantindo a efetividade das medidas preventivas e a sustentabilidade ambiental da atividade produtiva, mediante o gerenciamento e a autofiscalização necessários para manter o certificado.

Uma pesquisa realizada por Pardini, 2009, concluiu que cerca de $40 \%$ das empresas entrevistadas desconhecem a existência de certificações ambientais além de $21 \%$ que consideram ter pouco conhecimento na questão. Já a pesquisa realizada por Furuya e Oliveira, 2017, feita oito anos após a pesquisa de Pardini, mostrou que $94,3 \%$ dos entrevistados tem conhecimento das certificações ambientais.

Segundo Leite, 2011, a certificação ambiental é um instrumento interessante que possui grande potencial de implementar melhores práticas sustentáveis no setor, cria e cobra condições dos empreendimentos os tornando sustentável e atingem também os setores que servem de apoio.

Segundo Côrrea, 2006, o Brasil é reconhecido como um dos países com uma das legislações mais avançadas em relação à necessidade de proteção do meio ambiente, porém é preciso buscar novos meios para colocála em prática e intensificar os já existentes.

A importância de instrumentos de avaliação e reconhecimento, que levam à aplicação dos sistemas de avaliação e certificação como forma de apoiar a implementação e reconhecer objetivamente a procura de sustentabilidade, podem ser um contributo importante para a sua concretização (PINHEIRO, 2006).

\section{CONSIDERAÇÕES FINAIS}

A comparação realizada evidencia a amplificação das discussões a respeito dos conceitos e funções das certificações ambientais mesmo não ocorrendo na proporção desejada. Portanto é possível afirmar que embora o tema esteja evoluindo lentamente, o progresso é notável e contínuo.

\section{REFERÊNCIAS}

CORRÊA, D.R. Certificação ambiental, desenvolvimento sustentável e barreiras à entrada. Brasília a. 43 n. 169 jan./mar. 2006. Disponível em:

$<$

https://www2.senado.leg.br/bdsf/bitstream/han dle/id/496901/RIL169.pdf?sequence=1\#page=18 $\underline{8}>$. Acesso em 25 de agosto de 2018 .

DIAS, Reinaldo. Gestão ambiental: responsabilidade social e sustentabilidade. São Paulo: Atlas, 2009.

FURUYA, M.T.G e OLIVEIRA, R.C. O marketing e a educação ambiental como elementos constituintes da arquitetura sustentável. ETICEncontro Toledo de Iniciação Científica, v. 13, n. 13 (2017).

KEELER, M; BURKE, B. Fundamentos de projeto de edificações sustentáveis. Porto Alegre: Bookman, 2010, 362 p.

LEITE, V.F. Certificação Ambiental na Construção Civil - sistemas LEED e AQUA. Belo Horizonte, 2011. Disponível em: < http://pos.demc.ufmg.br/novocecc/trabalhos/pg 2/76.pdf > . Acesso em 25 de agosto de 2018.

PARDINI, A. F. Contribuição ao entendimento da aplicação da certificação LEED e do conceito de custos no ciclo de vida em empreendimentos mais sustentáveis no Brasil. 2009.

VIDIGAL, I.P.N. A certificação ambiental como instrumento para a competitividade econômica e o desenvolvimento sustentável, 2012. Disponível em: < http://www.publicadireito.com.br/artigos/?cod= 3b3dbaf68507998a>. Acesso em 26 de julho de 2018.

ZANGALLI, P.C. Jr. Sustentabilidade urbana e as certificações ambientais na construção civil. Soc. \& Nat., Uberlândia, 25 (2): 291-302, maio/agosto/2013. Disponível em: < http://www.redalyc.org/html/3213/3213287500 07/>. Acesso em 26 de julho de 2018. 